\title{
Counseling as Treatment for Major Depressive Disorder (MDD) in a Woman Participating Radical Organization: A Case Study
}

\section{Hasna Nadira ${ }^{a}$ and Indira Primasari ${ }^{\mathrm{b}}$}

$a_{\text {Faculty of Psychology, Universitas Indonesia, Depok, Indonesia; }}{ }^{b}$ Department of Clinical Psychology, Faculty of Psychology, Universitas Indonesia, Depok, Indonesia

*Corresponding author:

Indira Primasari

Department of Clinical Psychology

Faculty of Psychology, Universitas Indonesia

Jl. Lkr. Kampus Raya, Depok, Jawa Barat

Indonesia, 16424

Tel.: +62 217270004

Email address: indiraprimasari@ui.ac.id / indira.primasari@gmail.com 


\title{
Counseling as Treatment for Major Depressive Disorder (MDD) in a Woman Participating Radical Organization: A Case Study
}

\begin{abstract}
Depression is one of the most common mental disorders worldwide. Despite the bulk of literature on effective treatments for Major Depressive Disorder (MDD) that has been published, the discussion regarding treatment for depression related to involvement in radical organizations has remained sparse in recent publications. Based on the increase in radical organization involvement in society, additional research is needed. This clinical case study describes the assessment and treatment of a 30-year-old woman with MDD symptoms. The participant in this study reported symptoms of MDD, that is, a sense of emptiness, worthlessness, insomnia, loss of energy, and recurrent suicidal ideation. These symptoms have been present during the 6 months after the completion of her study, and she had no outside activities. Moreover, she felt disappointed and regretted her life. In addition to showing MDD symptoms, she also restricted interpersonal contact. She became relatively isolated and did not have extensive social support that could help her weather crises. Considering that counseling by a mental health professional has been used to help people develop more effective, satisfying, and productive ways of living, counseling may be a good fit for the treatment. This research uses a pre-post single-subject design. For this research, we use the Beck Depression Inventory (BDI) as the psychological measurement. The data obtained from the BDI is also supported by observations and an interview during the session. Based on the interview, this case study is in accordance with the humanistic approach. Therefore, counseling was chosen as a method for the treatment. To manage these symptoms, the intervention was held in five sessions (90-120 minutes each). Data analysis is conducted qualitatively by comparing the BDI score before and after the intervention. After five sessions of intervention and 5 months of follow-up, MDD symptoms display a clinically significant decrease. Depressive symptoms as measured by the BDI demonstrate a clinically significant reduction from 28 at pretreatment to 10 at the 5-month follow-up. The effectiveness of the treatment was also measured by using an interview and observations in every session. In the last session of the intervention, the participant reported that she no longer has suicidal ideation and attempted to open up to her mother. Additionally, 5 months after the last session, the participant conveyed that she is occupationally functioning and willing to open herself up to not only to her mother but also her friends. She also has an awareness to develop her passion.
\end{abstract}

Keywords — counseling, major depressive disorder, depression, radical organization

\section{Introduction}

Currently, radicalization has emerged to be one of the world's most serious threats that may result in physical and psychological effects on millions of people (Kruglanski, Gelfand, Belanger, Sheveland, Hetiarachchi, \& Gunaratna, 2014). A survey conducted by the Indonesian National Agency for Combating Terrorism, or Badan Nasional Penanggulangan Terorisme (BNPT), in 2017, found that 32 provinces in Indonesia showed an alarming rate of potential radicalism and scored 55,12 on a scale of 0-100 (BNPT, 2017). 
By definition, radicalism is a type of attitude that desires total and revolutionary changes by committing violence and extreme actions (Hendropriyono, 2009). Related to psychological aspects, radicalism could be associated with poor mental health (Coid, Bhui, MacManus, Kallis, Bebbington, \& Ullrich, 2016). Research found that mental disorders may induce vulnerability to radicalizing influences (Borum, 2014). The lack of personal identity combined with unfulfilled needs of belonging may be a factor that may confer personal crisis and act as a trigger to explore and adopt new beliefs and values that develop into radicalization (Coid et al., 2016).

In radicalization, people tend to use collectivities as their self-identity rather than individuals (Kruglanski, Gelfand, \& Gunaratna, 2012). Having a collective identity can make people become very engaged and encourage them to sacrifice on behalf of the group (Kruglanski et al., 2014). However, when they are no longer the part of the group, they tend to lose their identity, which threatens their mental health. One of the mental disorders that relate to this case is depression (Coid et al., 2016).

Depression is a mood disorder characterized by a persistent feeling of sadness and loss of pleasure (Kring, Johnson, Davison, \& Neale, 2013). As defined in the Diagnostic and Statistical Manual of Mental Disorders, fourth edition, text revision (DSM-IV-TR), depression typically presents in adolescence or early adult life (Arch, 2014). According to a World Health Organization (WHO) survey from 2015, the total number of people suffering from depression in the world was 322 million. Based on the data, depression is more common among females $(5,1 \%)$ than males $(3,6 \%)$ (World Health Organization, 2017). The high prevalence of depression has resulted in it becoming a major public health concern worldwide.

Major Depressive Disorder (MDD) is one of the most prevalent mood disorders (Kring et al., 2013). Several risk factors are related to MDD, that is, insufficient social resources, insufficient personal control, childhood abuse, various health risk behaviors, and stressful or traumatic life events (Peltzer \& Pengpid, 2015). As mentioned in the DSM-IV-TR, MDD is characterized by having a depressed mood most of the day, loss of pleasure, significant weight loss, insomnia, psychomotor agitation, fatigue, feelings of worthlessness, diminished ability to concentrate, and recurrent suicide ideation. Considering the consequences of the disabilities and loss of functions that might be caused, the WHO mentioned that MDD, compared with other mental disorders, would be one of the most significant challenges regarding management of mental disorders in the twenty-first century (Matsuzaka, Wainberg, Pala, Hoffmann, Coimbra, Braga, Sweetland, \& Mello, 2017).

Several treatment approaches have been developed for depression: interpersonal psychotherapy, behavioral activation therapy, behavioral couples' therapy, pharmacotherapy, cognitive-behavior therapy, or combination of one or more of these therapies (Kring et al., 2013; Wu, Brothers, Farrar, \& Andersen, 2014). According to Improving Access to Psychological Therapies (IAPT), CBT and Counseling for Depression are the two most widely accessed interventions for treating depression (Health and Social Care Information Centre, 2017). The result of the comparative study conducted by Pybis, Saxon, Hill, and Barkham 
(2017) to compare CBT and counseling as a treatment for depression showed that both treatments are effective to decrease depressive symptoms. Notably, CBT is more effective because the treatment has more than eight sessions, and counseling is more effective for therapies with less than eight sessions. Moreover, counseling also effective to prevent relapse of depression (Wu et al., 2014). Considering that this clinical case study is in accordance with the humanistic approach, counseling was used as the method for the treatment.

By definition, counseling is a treatment used to facilitate an individual's development of selfknowledge, emotional acceptance and growth and to develop personal resources (Gladding, 2018). Counseling may involve discussing life events, feelings, emotions, relationships, ways of thinking, and patterns of behavior (Pybis et al., 2017). When using counseling, the therapist must express honesty, openness, and a genuinely helpful attitude. Therefore, the skill of being an emphatic and sympathetic listener is essential for a therapist (Austad, 2009). To help clients improve their understanding of themselves and find their own solution to cope with their situation, the therapist listens, encourages, empathizes, and challenges their client to help the client see their issues more clearly and in different ways (Pybis et al., 2017).

This case study reports on the effectiveness of counseling for treating depression in a woman participating in a radical organization. According to the data in the literature on potential radicalism in Indonesia, further research for treatments related to radical organization involvement needs to be conducted because of the limited amount of research on this critical topic.

\section{Case Introduction}

\section{A. Participant}

To protect the participant's confidentiality, the pseudonym "Lola" was used. Lola was a 30year-old Indonesian woman and provided informed consent for this case report. We changed details regarding the participant's identification to ensure anonymity.

\section{B. Presenting Complaints}

At the intake assessment, Lola presented MDD symptoms, that is, a sense of emptiness and feelings worthlessness, disappointment, and regret. Lola reported difficulty sleeping, a loss of energy, and getting easily tired without doing any activities. Lola also has difficulty regulating her emotions. These symptoms have been present in the last 6 months after the completion of her study. Without any bustle, Lola often contemplated her life, and these contemplations aggravated her feelings of worthlessness and triggered suicidal ideations.

\section{Case History}

Lola described that she felt tense during her childhood. During her childhood, Lola's parents quarreled almost every day. At the time of the interview, Lola reported that her relationships with her parents and her siblings were not close relationships. Her father used an authoritarian parenting style, and she was not allowed to dispute her father. Lola felt worthless and afraid of her father. She kept being obedient even though she felt her parents never appreciated her. 
Additionally, Lola's mother did not spend much time with her, and Lola reported that she felt like nobody cared for her.

From the age 7 to 17 years, Lola's schoolmates bullied her. Since that time, Lola has not made friends. The schoolmates that bullied Lola based their cruelty on their perceptions of her physical appearance. She felt ashamed and worthless. She stated that she deserved to be abused because she had an unattractive appearance, unlike her schoolmates. Her negative thoughts made her feel insecure when she had to interact with people. Therefore, Lola preferred to isolate herself.

During college, Lola's self-confidence increased. The feelings of acceptance were because her new schoolmates based their impressions on her intelligence. To develop herself, she joined several organizations. Persuaded by one of her friends, Lola joined a radical organization. During her involvement in the radical organization, Lola was very engaged with the organization and stopped being involved in other organizations. She spent most of her time with the radical organization. After a few years of involvement, Lola quit the radical organization. Lola had realized that her life had become more chaotic since becoming a member. For example, she had incurred many debts and was unemployed. In addition, she was failing some classes and felt left behind because her friends had graduated. Lola had again developed low self-confidence. At that time, Lola attempted to overcome her depression by keeping busy. However, when the bustle settled, she could not deal with it. She regretted her life and began having suicidal ideations. Her tendency to isolate herself resulted in an insufficient social support system; thus, nobody was available to help her cope with crises.

\section{Methods}

\section{A. Research Design}

The design of this research was a pre-post single-subject design. We monitored Lola's depressive symptoms before, during, and after the intervention.

\section{B. Assessment}

The depressive symptoms were measured using the Beck Depression Inventory (BDI), which we translated into the Indonesian language. The BDI is a 21-item self-report measurement of depressive symptoms (Beck, Steer, \& Garbin, 1988). The Cronbach's alpha of BDI is 0,81, and this score shows a satisfactory rate of external validity because of its correlation with the Hamilton Rating Scale for Depression, which scored 0,73 (Beck et al., 1988). Additionally, the Cronbach's alpha of the adapted BDI scored 0,81 . Total scores are obtained by summing responses from each item, and higher scores indicate greater depressive symptoms. Lola's initial score was 28 , indicating severe depressive symptoms.

\section{Assessment Result}

Lola presented as sluggish and often looked down during the intake assessment session. Nevertheless, Lola could maintain eye contact with the counselor. The tone and volume of her 
speech were normal. In every session, Lola was observed to be friendly and cooperative. She easily had insight into her problems. Considering that the researcher was a clinical psychologist, the researcher could diagnosis Lola. Her multiaxial diagnosis is in Table 1.

Table I. Multiaxial Diagnosis for Lola

\begin{tabular}{|c|l|l|}
\hline Axis I & $296.2 x$ & Major Depressive Disorder \\
\hline Axis II & V71.09 & No Diagnosis \\
\hline Axis III & V71.09 & No Diagnosis \\
\hline Axis IV & & $\begin{array}{l}\text { Problems with primary support } \\
\text { group, problems related to the social } \\
\text { environment, occupational } \\
\text { problems, economic problems }\end{array}$ \\
\hline Axis V & $\begin{array}{l}\text { GAF }=61 \text { (at admission) } \\
\text { GAF }=70 \text { (at discharge) }\end{array}$ \\
\hline
\end{tabular}

${ }^{*}$ Note. Multiaxial diagnosis was made in accordance to Diagnostic Statistical Manual of Mental Disorders (Diagnostic and Statistical Manual of Mental Disorders; $4^{\text {th }}$ ed., text rev.; DSM-IV-TR; American Psychiatric Association, 2000).

\section{Procedure}

The treatment comprised five sessions (90-120 minutes each) focused on establishing rapport and counseling. In addition to using counseling, we provided her with a relaxation technique to help increase her tranquility, in particular, related to her unstable emotions. According to Jongsma, Peterson, and Bruce (2014) the treatment for depression aims to increase the awareness due to depressive symptoms, develop healthy beliefs about the self, develop healthy interpersonal relationships, and normalize mood to return to the adaptive level of functioning (2014). Referring to that objective, Lola's treatment was administered with a counseling approach divided into the following phases.

\section{E. Course of treatment}

\section{1) Session 1}

In session 1, we focused on building a trusted relationship with Lola. She was asked to explain her problems. Lola described all the symptoms she had. Based on Lola's explanations, the counselor helped Lola identify the causes of her depression. By using counseling, the counselor and Lola tracked her past experiences related to her depression. Lola was also asked to identify any situation that triggered her feeling of worthlessness. Lola cried when she discussed her past experienced. The counselor helped Lola express her feelings of hurt, shame, anger, and disappointment associated with her life experiences. While talking about her experiences, Lola had difficulty regulating her emotions. At the end of the session, the counselor provided relaxation techniques to help Lola reduce tension and to feel more serene. 


\section{2) Session 2}

In session 2, Lola attended the session by showing her resentment. Lola cried and emphasized her suicidal ideation. Based on Lola's condition, the session began by providing relaxation to Lola. In this session, the treatment focused on Lola's suicidal ideation. Lola was asked to identify and realize any situation that triggered her suicidal ideation. She reported that her suicidal ideation was triggered by the suicide of her schoolmate. Since that time, Lola reported having suicidal ideations every time she felt humiliated when people asked about her life. These interactions made her contemplate her life and aggravated her feeling of worthlessness. Eventually, Lola realized that she had no goals to achieve in life. This condition made Lola feel as if her life had no purpose and triggered suicidal ideation. The counselor and Lola created a long-term and short-term treatment plan related to her condition.

\section{3) Session 3}

In session 3, Lola informed the counselor that she had a tendency to injure herself by hitting herself that began when she was 10 years old. Lola realized that she did not want to actually hurt herself, but the behavior was a means to express her resentment. As such, Lola and the counselor discussed how to help Lola compensate for her tendency to injure herself. The counselor assisted Lola to develop coping strategies, namely, increasing physical exercise, social involvement, and activities and decreasing internal focus. Additionally, the counselor assisted Lola regarding becoming aware of people that could be part of her support system to help her weather crises. From the discussion, Lola realized that she could rely on her mother to be the main person in her support system. Moreover, the counseling in this session also focused on Lola's interpersonal relationships. Lola was asked to identify the obstacle to her interpersonal relationships. She realized that she wanted to have close friends, but all this time, she had withdrawn herself from the people around her even though others were attempting to make friends with her.

\section{4) Session 4}

In session 4, the counselor reviewed Lola's depressive symptoms. Lola claimed that she no longer had suicidal ideation. Lola attempted to open herself up to her mother, and to Lola's surprise, her mother cared about Lola's condition and was willing to support her. Lola reported feeling better after sharing her problems with her mother. Nevertheless, Lola continued to have difficulties alleviating her negative thoughts about herself. Moreover, Lola realized that her negative thoughts appeared because of her tendency to compare herself with others. Hence, Lola felt inferior to other people. To help Lola cope with her negative thoughts, the counselor asked Lola to recognize and find evidence of her negative thoughts. The counselor provided Lola with a homework assignment: write a daily journal entry of her negative thoughts.

\section{5) Session 5}

In session 5, Lola's physical appearance demonstrated no observable sign of depression during the session. Lola presented as vibrant and cheerful. She told the counselor that she had a few days ago. That time was the first time that Lola's parents showed appreciation 
toward her, and the experience increased her reported sense of self-worth. In this session, Lola was assisted so that she could identify her potential. Lola and the counselor discussed how to help Lola develop her potential. Lola realized that she needs to find a community to increase her social involvement and develop her passion. The counselor provided Lola with a homework assignment: write a positive affirmation statement daily regarding herself and the future. Before the session ended, the counselor conducted the BDI to assess her depression. Her total score on the BDI was 21 and had decreased compared with the baseline score.

\section{6) Follow up}

The follow-up session was conducted 5 months after session 5 to monitor whether Lola could maintain the relapse of her depression. The BDI was administered to assess Lola's depressive symptoms. The total score at follow-up was 10, which indicated mild depressive symptoms.

When attending the follow-up session, Lola presented as neat. She used make-up on her face, which differed from sessions 1 to 5 . She looked vibrant and talked a lot during the session. Lola reported that after the last treatment session, she had continued practicing coping with her negative thoughts; attempted to open herself up by joining the art community to increase her social involvement and develop her passion; and was occupationally functioning and had started to consider the goals she wants to achieve. The awareness about her goals had encouraged Lola to make plans, and she felt her life had purpose. Additionally, Lola continued to practice the relaxation techniques to help her regulate her emotions and when she has difficulties sleeping.

\section{Results}

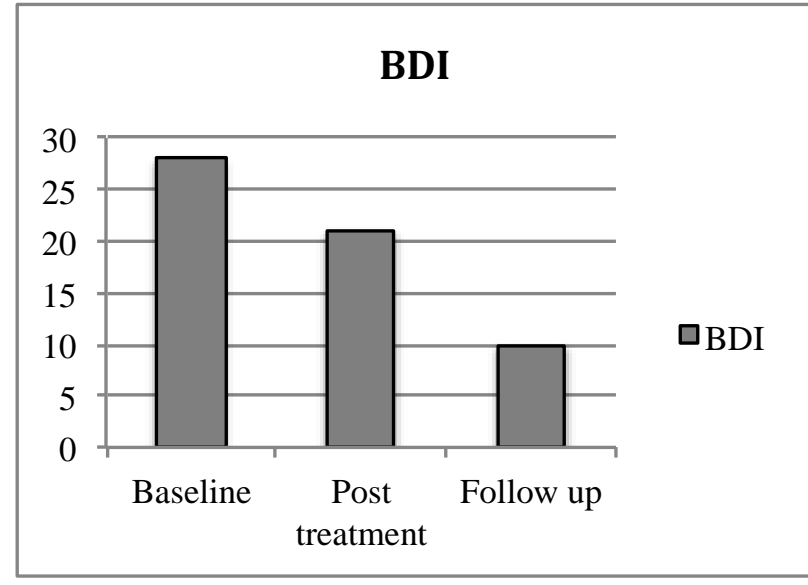

Fig. 1. Measurement of depressive symptoms during the course of treatment

From the data in Figure 1, we concluded that Lola's depressive symptoms were gradually declining. At the baseline, Lola's depressive symptoms were in the significant clinical range. At post-treatment, her depressive symptoms had declined to a near-moderate level, and at follow-up, her depressive symptoms had declined to a mild level. 


\section{Discussion and Conclusion}

Consistent with another study, we assert that radicalism might be associated with poor mental health (Coid et al., 2016). This phenomenon was observed in Lola, who experienced a substantial amount of pressure since her childhood that made her vulnerable and a more recent influence from radicalization. Therefore, the intervention for Lola focused on building good mental health through the counseling process.

In general, the result shows that intervention through counseling could help reduce depressive symptoms in a woman who had participated in a radical organization. This result was achieved through five sessions and is in line with the preliminary studies that have indicated that counseling might be effective to treat depression for a client in less than eight sessions (Pybis et al., 2017). The effectiveness of counseling is also supported by the client factor. As Tallman and Bohart argued, the client is the engine that drives successful counseling (Tallman \& Bohart, 1999). In addition, according to Leibert (2011) client openness predicted $80 \%$ positive outcomes from counseling [20]. In this case study, Lola was cooperative and highly open to advice. Her ability to gain insights and her motivation also helped Lola cope with the problems she reported. After the last session of the treatment, Lola attempted to maintain her improved condition by practicing the techniques discussed in the sessions.

Other factors that helped Lola reduce her depressive symptoms are related to external factors. In the process of the intervention, Lola attempted to open up to her mother, and unexpectedly, her mother provided support. Moreover, the appreciation from Lola's parents during her graduation was also helpful with increasing her self-worth. In line with the research conducted by Wang Cai, Qian, and Peng (2014) social support helped to alleviate harmful effects of a stressful experience, enhanced coping strategies, and provided problem-solving strategies (Wang et al., 2014). Thus, we assert that social support can reduce the intensity of depression. In Lola's case, after graduating, she attempted to find a community and a job to fill her time not spent with family. Through the community and her job, Lola received support, which decreased her depression to some degree.

Although the result of the study demonstrates that counseling is effective to reduce depression, the study has limitations. First, because the study is a single-case study, the result of the study is not generalizable. Second, external factors affected Lola's decreased depression, that is, support from her mother and appreciation from her parents at her graduation. Therefore, further research should control the external variables to ensure that the contribution provided by the intervention can be clearly observed. Moreover, the intervention in this case study can also be replicated to be more systematic to improve treatment effectiveness.

\section{Authors' Note}

Regarding the participant's consent, there are several aspects that were not stated in this paper. 


\section{References}

Arch, J. J. (2014). Behaviour research and therapy cognitive behavioral therapy and pharmacotherapy for anxiety: Treatment preferences and credibility among pregnant and non-pregnant women. Behaviour Research and Therapy, 52, 53-60.

Austad, C. S. (2009). Counseling and psychotherapy today: Theory, practice, and research. New York, NY: McGraw-Hill.

Beck, A. T., Steer, R. A., \& Garbin, M. G. (1988). Psychometric properties of the Beck Depression Inventory: Twenty-five years of evaluation. Clinical Psychology Review, 8(1), 77-100.

BNPT. (2017). Potensi radikalisme masyarakat Indonesia perlu diwaspadai. Tempo.

Borum, R. (2014). Psychological vulnerabilities and propensities for involvement in violent extremism. Behavioral Sciences \& the Law, 32(3), 286-305.

Coid, J. W., Bhui, K., MacManus, D., Kallis, C., Bebbington, P., \& Ulrich, S. (2016). Exterimism, religion, and psychiatric morbidity in a population-based sample of young men. British Journal of Psychiatry, 209(6), 491-497.

Gladding, S. T. (2018). Counseling: A comprehensive profession. Boston: Pearson.

Health and Social Care Information Centre (HSCIC). (2015). Improving access to psychological therapies report. Retrieved from http://www.hscic.gov.uk/catalogue/ PUB17755 on 9 April 2017.

Hendropriyono, A. M. (2009). TERORISME - ISIS. BNPT, 1-6.

Jongsma, A. E., Peterson, L. M., \& Bruce, T. J. (2014). The complete adult psychotherapy treatment planner. Hoboken, NJ: John Wiley and Sons, Inc.

Kring, A. M., Johnson, S. L., Davison, G. C., \& Neale, J. M. (2013). Abnormal Psychology. Hoboken, NJ: Wiley.

Kruglanski, A. W., Gelfand, M., Belanger, J. J., Sheveland, A., Hetiarachchi, M., \& Gunaratna, R. (2014). The psychology of radicalization and deradicalization: How significance quest impact violent extremism. Political Psychology, 35(1), 69-93.

Kruglanski, A. W., Gelfand, M., \& Gunaratna, R. (2012). Terrorism as means to an end: How political violence bestows significance. PsycEXTRA Dataset.

Leibert, T. W. (2011). The dimension of common factors in counseling. International Journal of Advanced Community Medicine, 33(2), 127-138.

Matsuzaka, C. T., Wainberg, M., Pala, A. N., Hoffmann, E. V., Coimbra, B. M., Braga, R. F., ... \& Mello, M. F. (2017). Task shifting interpersonal counseling for depression: A pragmatic randomized controlled trial in primary case. BMC Psychiatry, 17(1), 1-11.

Peltzer, K., \& Pengpid, S. (2015). Depressive symptoms and social demographic, stress, and health risk behaviour among university students in 26 low-, middle-, and high-income countries. International Journal of Psychiatry in Clinical Practice, 19(4), 260-266.

Pybis, J., Saxon, D., Hill, A., \& Barkham. (2017). The comparative effectiveness and efficiency of cognitive behaviour therapy and generic counselling in the treatment of depression: Evidence from the $2^{\text {nd }}$ UK National Audit of psychological therapies. BMC Psychiatry, 17(1), 1-13.

Tallman, K. \& Bohart, A. C. (1999). The client as a common factor: Client as self-healers. The heart and soul of change: What works in therapy, 91-131.

Wang, X., Cai, L., Qian, J., \& Peng, J. (2014). Social support moderates stress effects on depression. International Journal of Mental Health Systems, 8(1), 1-5.

World Health Organization. (2017). Depression and other common mental disorders: Global health estimates. World Health Organization, 1-24.

Wu, S. M., Brothers, B. M., Farrar, W., \& Andersen, B. L. (2014). Individual counseling is the preffered treatment for depression in breast cancer survivors. Journal of Psychosocial Oncology, 32(6), 637-646. 